\title{
Seasonality in onshore normalized wind profiles above the surface layer
}

\author{
J. N. Nissen and S.-E. Gryning \\ Ris $\varnothing$ National Laboratory for Sustainable Energy, Technical University of Denmark, Frederiksborgvej 399, \\ P.O. Box 49, 4000 Roskilde, Denmark
}

Received: 14 January 2010 - Revised: 15 March 2010 - Accepted: 24 March 2010 - Published: 12 May 2010

\begin{abstract}
This work aims to study the seasonal difference in normalized wind speed above the surface layer as it is observed at the $160 \mathrm{~m}$ high mast at the coastal site Høvsøre at winds from the sea (westerly).

Normalized and stability averaged wind speeds above the surface layer are observed to be 20 to $50 \%$ larger in the winter/spring seasons compared to the summer/autumn seasons at winds from west within the same atmospheric stability class.

A method combining the mesoscale model, COAMPS, and observations of the surface stability of the marine boundary layer is presented. The objective of the method is to reconstruct the seasonal signal in normalized wind speed and identify the physical process behind. The method proved reasonably successful in capturing the relative difference in wind speed between seasons, indicating that the simulated physical processes are likely candidates to the observed seasonal signal in normalized wind speed.
\end{abstract}

\section{Introduction}

An increasing demand for the ability to estimate the wind climate above the surface layer in coastal regions has been generated by the wind power industry because of the steady increase of modern wind turbines with hub heights well above the surface layer height. To choose the optimal site for a wind turbine, information about the wind energy potential needs to be properly assessed. The wind energy potential is proportional to the cube of the wind speed at hub height, implying that even a small error in estimating the wind speed can have a large impact on the wind energy assessment. Conventional methods for assessing wind speed at heights of up to $200 \mathrm{~m}$, such as that of Troen and Lundtang (1989), are derived from wind measurement taken close to the surface and extrapolated to greater heights by assuming a logarithmic increase of the wind speed with height, with a correction for stability effects. The derivation of the logarithmic wind profile assumes homogeneous surface properties and a constant momentum flux and is therefore confined to the surface layer. Little is known about boundary layer wind profiles above the surface layer, but recent attempts to address this

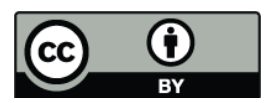

Correspondence to: J. Nielsen Nissen (jesper.nissen@risoe.dk) problem have been put forward by Högström et al. (2006) and Gryning et al. (2007), where extension to the MoninObukhov surface similarity scaling is suggested with some success. In a coastal region, the description of the wind profile is however complicated by non-homogenous upstream surface conditions, orography, change of roughness and heat capacity, all of which influence the wind profile and are difficult to describe using simple, universal formulas. An observational study is undertaken in order to quantify the effects on the wind profile from the upstream surface conditions. The observed effects are caused by multiple boundary layer processes at play in the coastal boundary layer and in order to identify the most significant ones, we apply a well-validated mesoscale model in an idealized setup. The selected boundary layer processes in the idealized modelling are kept under easy control and we are therefore able to test the models ability to reproduce the observed wind profile in an idealized atmosphere where only a few boundary layer processes are at play.

\section{Observations}

The observational basis for this work consists of measurements from the Høvsøre National Test Station for Large Wind Turbines situated in the northwestern part of Denmark (Fig. 1). The data is gathered during the period from 


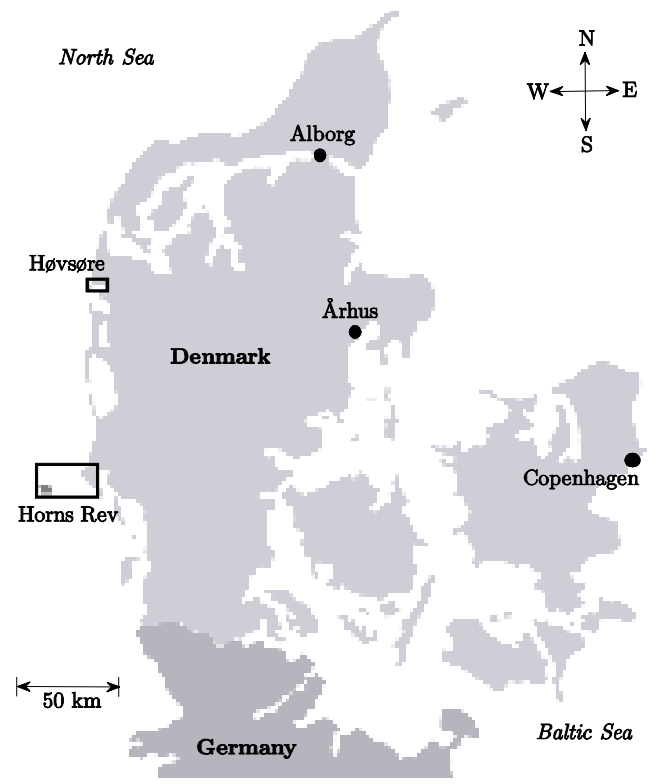

Figure 1. Høvsøre and Horns Rev position.

February 2004 to May 2008 for the onshore wind direction sector $260^{\circ}-280^{\circ}$.

Upstream observations of the stability distribution in the marine boundary layer were found to be of importance in describing the seasonal differences in the normalized wind profiles at Høvsøre and measurements from offshore wind park Horns Rev were therefore used. To classify the stability for the Høvsøre observations, the Obukhov length, $L$, defined in Eq. (1), is evaluated from the Høvsøre sonic anemometer mounted at $20 \mathrm{~m}$ height. The observations are subsequently sorted into 7 stability bins following Gryning et al. (2007) and normalized by the friction velocity at $20 \mathrm{~m}$ as defined in Eq. (2) and finally averaged according to season.

$L=\frac{-u_{* 20 \mathrm{~m}}^{3}}{\kappa\left(g / T_{20 \mathrm{~m}}\right)\left(\overline{w^{\prime} T^{\prime}}\right)_{20 \mathrm{~m}}}$

$\kappa=$ von Karman constant

$g=$ Acceleration of gravity

$T=$ Temperature

$u_{* 20 \mathrm{~m}}^{2}=\left[{\overline{u^{\prime} w_{20 \mathrm{~m}}^{\prime}}}^{2}+{\overline{v^{\prime} w_{20 \mathrm{~m}}^{\prime}}}^{2}\right]^{0.5}$

The results from this procedure can be seen in Fig. 2. It is here observed how the seasons wind speed systematically splits at heights above $40 \mathrm{~m}$. The spring season is always the most windy (except for bin $-500<L<-200$ which is poorly represented for the winter season) and the summer is the less windy season. Winter and autumn falls systematically between the spring and summer seasons for all stability bins.
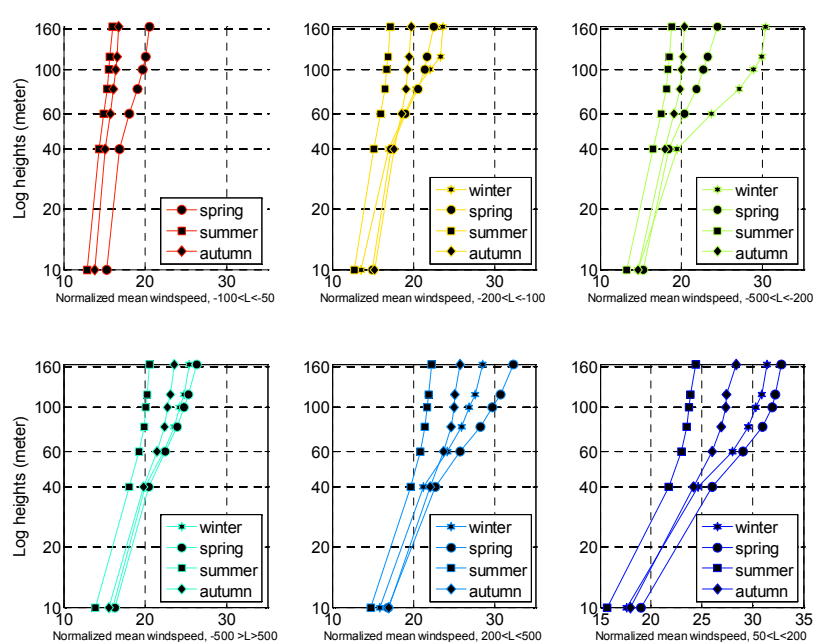

Figure 2. Observed stability-bin-averaged and normalized wind profiles for each season at Høvsøre for the onshore wind direction sector (260-280 degree west.)

\section{Method and physical process}

It was during this work observed, that the annual stability distribution between the coastal station Høvsøre (Fig. 3) and the upstream marine station Horns Rev (Fig. 4) was phase shifted. It is posed here that the associated boundary layer processes from the observed phase shift in annual stability distribution are responsible for the observed seasonal signal in the normalized wind profiles in the following way.

When a majority of observations reflect unstable marine atmospheric boundary layers (hereafter mabl), which is advected over a neutral coastal internal boundary layer (cibl), then the upper normalized wind profile will bend to the left (autumn and summer scenario, neutral case). The opposite will happen when the majority of observations reflect stable mabl's, which are advected over a neutral cibl and make the upper normalized wind profiles bend to the right (spring and winter scenarios, neutral case). The method presented here was designed to test this hypnosis's accordingly.

At Horns $\operatorname{Rev} L$ is calculated from the bulk Richardson number, following Grachev and Fairall (1996) in Eqs. (3) and (4) respectively, where $C_{1}=C_{2}=10$ and $C_{3}=5$.

$R i_{b}=\frac{g z(\Delta \theta)_{13 \mathrm{~m}-(-4 \mathrm{~m})}}{\theta_{13 \mathrm{~m}} u_{15 \mathrm{~m}}^{2}}$

$\frac{z}{L}=C_{1} R i_{b} \quad$ Unstable

$\frac{z}{L}=\frac{C_{2} R i_{b}}{1-C_{3} R i_{b}} \quad$ Stable

Modeling and result: The numerical method consists of 2 sets of simulations, denoted step 1 and step 2, and are conceptually outlined in Fig. 5. 


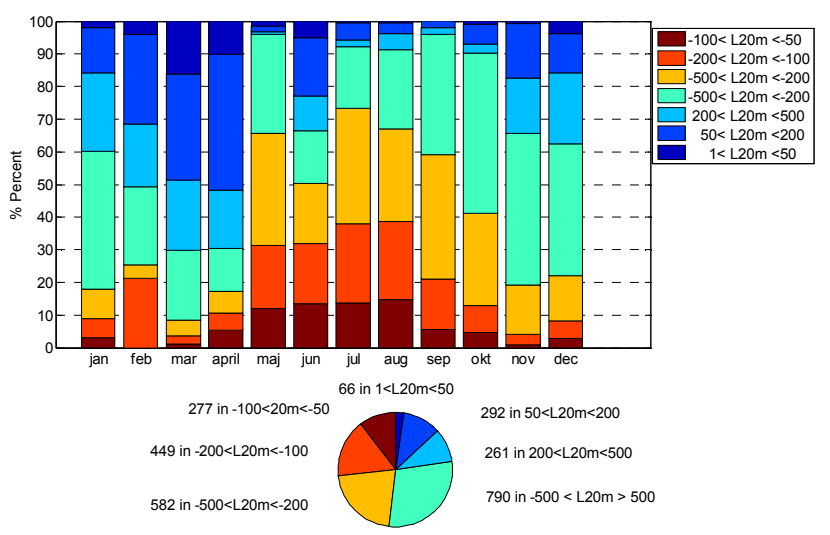

Figure 3. Høvsøre test station: monthly stability distribution (bar graph, upper) and yearly distribution of the stability distribution (pie chart, lower). Left hand integers denote number of observation in stability class (legend, lower).

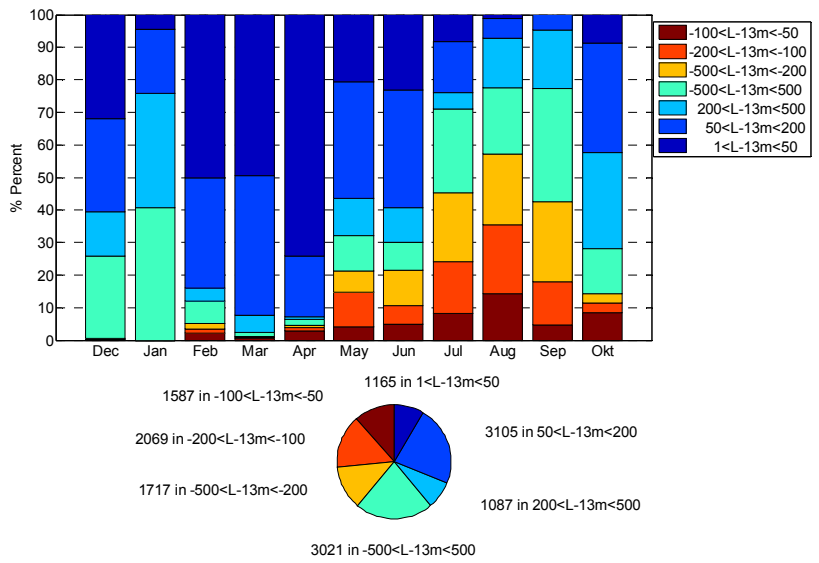

Figure 4. Horns Rev wind farm: monthly stability distribution (bar graph, upper) and yearly distribution of the stability distribution (pie chart, lower). Left hand integers denote number of observation in stability class (legend, lower). The data is from the period December 2003 to November 2004 , for the $225^{\circ}-315^{\circ}$ wind direction sector.

Step 1. Generation of 18 marine atmospheric boundary layers (mabl).

Procedure: In this step, air is allowed 6 different initial temperatures and is swept across a sea surface, which is kept at temperature $277 \mathrm{~K}$. The initial speed of the wind is varied from $10 \mathrm{~m} / \mathrm{s}$ over 15 to $20 \mathrm{~m} / \mathrm{s}$ and is initially constant with height. The marine atmospheric boundary layer is then spun up by the model and profiles of wind and temperature in equilibrium with the sea surface is generated during the $6 \mathrm{~h}$ of integration time.

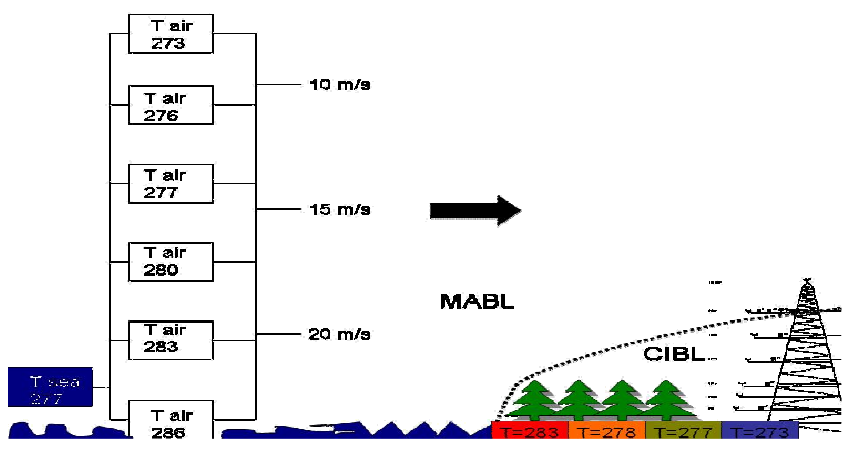

Figure 5. Conceptual model of the numerical method.

Step 2. Generation of 72 coastal wind profiles.

Procedure: The $18 \mathrm{mabl}$ are hereafter exposed to a cost line with 4 different temperatures. The end result of these two simulation steps is 72 simulations, where wind profiles are extracted from a position in the model domain relating to Høvsøre test station in terms of distance from the coast.

To make the extracted profiles comparable to the normalized and seasonal averaged observations from Høvsøre, an averaging procedure reflecting the particular season is needed. The observed phase shift in annual stability distribution over the North Sea is used to average the profiles in the following way. Each extracted wind profile is assigned a weight for each season reflecting how often the mabl it originates from occurs in that season. The seasonal weights are attained by assuming that a mabl is fully characterised by the computed surface $L$. The probability/weight of the mabl in a given season is then the same as the probability of the computed $L$ to occur in that season divided by the number of simulated mabl with the same $L$. The weight of each mabl for each season, depicted in Fig. 6, is then used to average the normalized wind profiles within each stability bin. This result is one wind profiles for each season and stability bin, as depicted in (Fig. 7) which is then immediately comparable to the observed wind profiles from Høvsøre (Fig. 2).

\section{Results and conclusions}

The observed seasonal pattern as seen in Fig. 2 is to some extent reproduced by the method as seen in Fig. 7. The relatively larger wind speeds observed in spring and winter is clearly detectable in all 4 simulated stability bins. Also the trend towards higher wind speed at the top of the seasonal averaged profile with increasing stability is clearly seen. The height of the equilibrium layer is also seen to be captured quite well to $40 \mathrm{~m}$. The experiment proved skill in predicting the seasonality in the normalized wind profiles for Høvsøre when incorporating information on the upstream stability distribution. Using the time lag in stability distribution in 


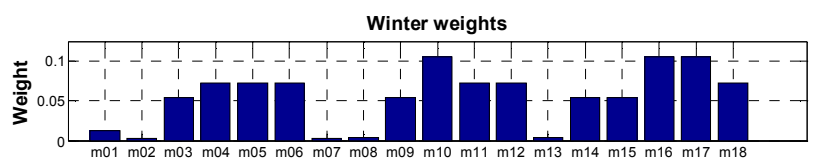

Spring weights

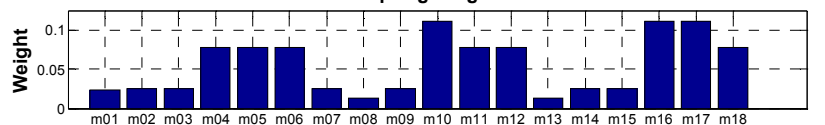

Summer weights

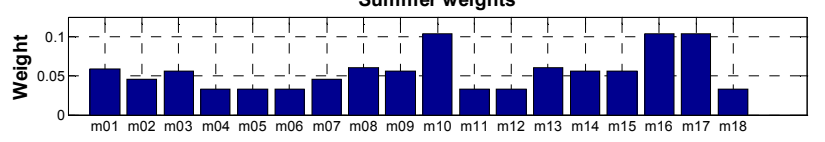

Autumn weights

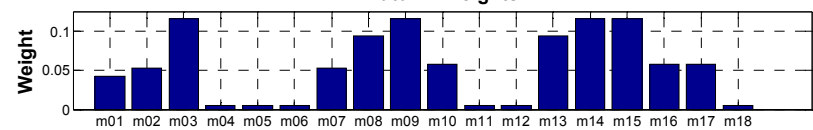

Figure 6. Seasonal weighs for the generated mabl. The syntax for the mabl is listed in Table A2.
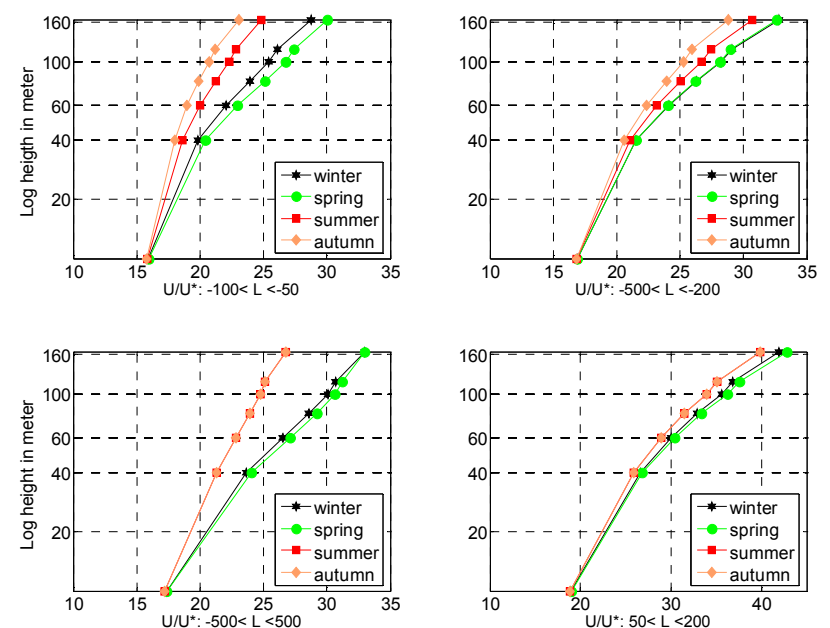

Figure 7. Simulated stability-bin-averaged and normalized wind profiles for each season at a position in model domain relating to Høvsøre.

terms of $L$ between the North Sea and Høvsøre made it possible to partially reproduce the observed seasonality indicating that some of the important physical processes behind the observations are captured in the idealized setup presented here. The observed normalized bin averaged wind profiles are, to a reasonable degree, seen to follow the conceptual model suggested by Sempreviva et al. (1990); Jensen and Peterson (1977). The wind profiles from $100 \mathrm{~m}$ and up are characterized by a smaller slope and according to Sempreviva et al. (1990) and Jensen and Peterson (1977) can the smaller slope be interpreted as an equilibrium with the upstream smoother sea surface. This feature is not captured in the numerical setup and the upper part of the simulated bin averaged wind profile is seen to be over predicted for all seasons and bins. The difference between the simulations and
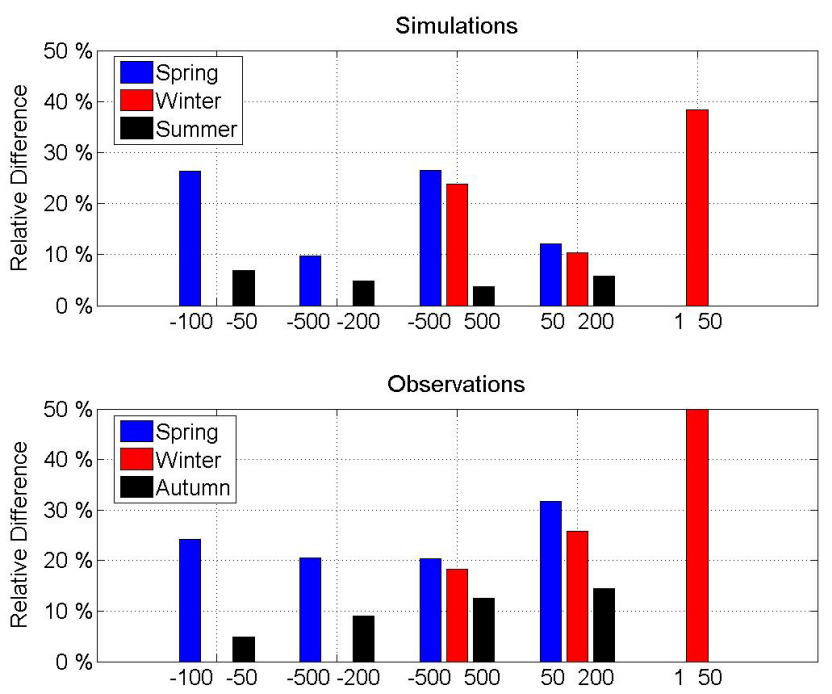

Figure 8. Simulated and observed relative difference between seasons at $100 \mathrm{~m}$ found according to Eqs. (5) and (6).

RD - winter $=\frac{\left.\text { Winter_Wspd }_{100 \mathrm{~m}}-\text { Autumn_Wspd }_{100 \mathrm{~m}}\right]}{\text { Autumn_Wspd }_{100 \mathrm{~m}}} 100$

Simulated profiles

$\mathrm{RD}-$ winter $=\frac{\left[\text { Winter_W }_{-} \mathrm{Wpd}_{100 \mathrm{~m}}-\text { Summer_Wspd }_{100 \mathrm{~m}}\right]}{\text { Summer_Wspd }_{100 \mathrm{~m}}} 100$

Observed profiles

the observations for wind speed above $100 \mathrm{~m}$ clearly shows that the highly idealized simulations utilities here does not capture correctly the boundary layer processes responsible for the mabl structures over the North Sea, as seen in the observations above $100 \mathrm{~m}$. The most likely explanation for this mismatch between the observations and the simulations is a possible too low simulated height of the averaged upstream constant flux layer. The conceptual model suggested by Sempreviva et al. (1990) and Jensen and Peterson (1977) assumes logarithmic upwind wind profile dictating an upwind average constant flux layer height of at least $160 \mathrm{~m}$ in order to diagnose the characteristically kink feature in the wind profile as seen in the observations from Høvsøre.

\section{Model skills relative comparison}

Better agreement between the observations and the simulations is found when comparing the relative differences, denoted RD, calculated as outlined in Eqs. (5), (6) and depicted in Fig. 8. The $100 \mathrm{~m}$ height is chosen for a number of reasons. The most important one is that it close to the height of the internal boundary layer at the position of the observations mast and therefore reflects both local and upstream properties. 
Table A1. Model details.

\begin{tabular}{|c|c|c|c|c|}
\hline \multicolumn{2}{|l|}{ Grid information } & \multicolumn{2}{|l|}{ Resolution } & \multirow[b]{2}{*}{$\begin{array}{l}\text { Boundary condition } \\
\text { Step 1: } \\
\text { Periodic } \\
\text { Step 2: } \\
\text { Western: Rayleight } \\
\text { damping on the inflow } \\
\text { Eastern, southern and } \\
\text { northern: Radiation } \\
\text { condition. }\end{array}$} \\
\hline $\begin{array}{l}\text { Nr. Horizontal grid points } \\
120(\mathrm{E}-\mathrm{W}) \\
60(\mathrm{~N}-\mathrm{S}) \\
\text { Step } 1 \\
120 * 60 \text { sea points } \\
\text { Step } 2 \text { : } \\
60 * 60 \text { land points } \\
60 * 60 \text { sea points }\end{array}$ & $\begin{array}{l}\text { Vertical } \\
62 \text { levels } \\
\text { Top: } 3825 \mathrm{~m}\end{array}$ & $\begin{array}{l}\text { Horizontal } \\
(50 * 50) \mathrm{m}\end{array}$ & $\begin{array}{l}\text { Vertical: } \\
10 \mathrm{~m} \text { below } 250 \mathrm{~m} \\
\text { hereafter stretched } \\
\text { gradually to } 200 \mathrm{~m} \\
\text { above } 1000 \mathrm{~m}\end{array}$ & \\
\hline Initial profile & & Surface & & ABL physics \\
\hline \multicolumn{2}{|c|}{$\begin{array}{l}\text { Profiles of wind speed and temperature ex- } \\
\text { tracted from the mabl simulations in step } 1 \\
\text { are used as initial profiles in step } 2 \text {. }\end{array}$} & \multicolumn{2}{|c|}{$\begin{array}{l}\text { Step 1: } \\
120 * 60 \text { grid points of constant sea } \\
\text { roughness }=0.0001 \mathrm{~m} \\
\text { Step 2: } \\
60 * 60 \text { grid points of } \\
\text { land roughness }=0.01 \mathrm{~m} \\
60 * 60 \text { grid points of } \\
\text { constant sea roughness } 0.0001 \mathrm{~m}\end{array}$} & $\begin{array}{l}\text { No moisture, no radiation } \\
\text { PBL scheme: } 1.5 \text { order, } \\
\text { level } 2.5 \text { (Mellor and } \\
\text { Yamada, 1982) } \\
\text { Surface layer : Louis (1979) } \\
\text { Mixing length: Blackadar } \\
\text { (1962) }\end{array}$ \\
\hline
\end{tabular}

Table A2. Syntax for the simulated mabl listed in Fig. 6.

\begin{tabular}{lccccccccc}
\hline mabl nr & $\mathrm{m} 01$ & $\mathrm{~m} 02$ & $\mathrm{~m} 03$ & $\mathrm{~m} 04$ & $\mathrm{~m} 05$ & $\mathrm{~m} 06$ & $\mathrm{~m} 07$ & $\mathrm{~m} 08$ & $\mathrm{~m} 09$ \\
\hline Wspd & 10 & 10 & 10 & 10 & 10 & 10 & 15 & 15 & 15 \\
Air tmp (K) & 273 & 276 & 277 & 280 & 283 & 286 & 273 & 276 & 277 \\
\hline mabl nr & $\mathrm{m} 10$ & $\mathrm{~m} 11$ & $\mathrm{~m} 12$ & $\mathrm{~m} 13$ & $\mathrm{~m} 14$ & $\mathrm{~m} 15$ & $\mathrm{~m} 16$ & $\mathrm{~m} 17$ & $\mathrm{~m} 18$ \\
\hline Wspd m/s & 15 & 15 & 15 & 20 & 20 & 20 & 20 & 20 & 20 \\
Airtmp (K) & 280 & 283 & 286 & 273 & 276 & 277 & 280 & 283 & 286 \\
\hline
\end{tabular}

Good agreement is found between simulations and observations for the most convective bin 1 as seen in Fig. 8. The observed relative difference between the high wind season (winter) and the low wind season (summer) is seen to be $24 \%$ while the simulations gave $26 \%$. The same good agreement is evident when comparing the second lowest to the lowest wind season, in the same stability class. Here observations read $4.8 \%$ and simulations $7.8 \%$. Similar good agreements are found in the neutral stability class. A general pattern was that we found good agreement for the stability bins with numerous observations and simulations, and not so good agreements were found for the bins with only a few observations and simulations. This is encouraging and indicates that the method captures the relevant physical processes behind the seasonality in the normalized wind profile and we can therefore conclude that the phase shift in annual offshore/onshore stability distribution plays a major role in the observed seasonality in the normalized onshore wind profiles.

\section{Summary}

We can summarize the findings as follows. The observational analysis showed that onshore normalized wind profiles at Høvsøre had a strong seasonal dependence and the modelling strongly indicated that this was caused by boundary layer processes, associated with the offshore/onshore phase shift in annual stability distribution. We expect the seasonality to be present on the entire west coast of Jutland and therefore recommend including offshore stability condition when addressing the wind resource climate at west coast stations in Jutland.

\section{Appendix A \\ Model details}

COAMPS is a finite-difference approximation to the nonhydrostatic fully compressible equations of motion following Klemp and Wilhemson (1977) with a suite of physical parameterizations of surface fluxes, boundary layer physics and moist processes described in Hodur (1997) and Hodur and Doyle (1998). The physical processes behind the 
parameterizations can be switched on and off in order to meet the complexity of the area of interest in the numerical experiment. Below is listed information on the model-setup during simulations carried out in this study.

Acknowledgements. This work was supported in part by the Danish Council for Strategic Research sagsnr. 2104-08-0025.

Edited by: A. M. Sempreviva

Reviewed by: two anonymous referees

\section{References}

Blackadar, A. K.: The vertical distribution of wind and turbulent exchange in a neutral boundary atmosphere, J. Geophys. Res., 67, 3095-3102, 1962.

Grachev, A. and Fairall, C.: Dependence of the Monin-Obukhov stability parameter on the Bulk Richardson number over the Ocean, J. Appl. Meteorol., 36, 406-414, 1996.

Gryning, S. E., Batcvarova, E., Brümmer, B., Jørgensen, H. E., and Larsen, S. E.: On the extension of the wind profile over homogeneous terrain beyond the surface layer, Bound.-Lay. Meteorol., 124, 251-268, 2007.

Hodur, R. M.: The Naval Research Laboratory's coupled Ocean/atmosphere meso scale predition system (COAMPS), Mon. Weather Rev., 125, 1414-1430, 1997.
Hodur, R. M. and Doyle, J. D.: The coupled ocean/atmosphere model prediction system COAMPS ". Coastal ocean predict, Coast. Estuar. Stud., 56, 125-155, 1998.

Högström, U., Smedman, A., and Bergström, H.: Calculation of the wind speed variation with height over the sea, Wind Engineering, 30, 269-286, 2006.

Jensen, N. O. and Peterson, E. W.: Wind flow near the surface of non uniform terrain, Report of progress for the year 1976 Progress report for US army grant available at Risø National Laboratory, 1976.

Klemp, J. B. and Wilhelmson, R. B.:The simulation of theredimensional convective storm dynamics, J. Atoms. Sci., 35, 1070-1096, 1977.

Mellor, G. L. and Yamada, T.: Development of a turbulence closure model for geophysical fluid problems, Rev. Geophys., 20, 851$875,1982$.

Sempreviva, A. M., Larsen, S. E., Mortensen, N. G., and Troen I.: Response of neutral boundary layers to change in Roughness, Bound.-Lay. Meteorol., 50, 205-226, 1990.

Troen, I. and Lundtang Petersen, E.: European Wind Atlas, Ris $\varnothing$ National Laboratory, Ris $\varnothing$, Denmark, 1989. 